\title{
To Study The Association of Thyroid Hypofunction With Increasing Age in Pregnant Women With Hypertension
}

\author{
Authors \\ Dr. Sanghmitra Singh ${ }^{1}$, Dr.Kalpana Yadav², Dr.Kshama Vishwakarma ${ }^{3}$ \\ ${ }^{1}$ Senior Resident, Department of Obstetrics and Gynaecology, S.S. Medical College, Rewa \\ ${ }^{2}$ Associate Professor and Head, Department of Obstetrics and Gynaecology,S.S. Medical College ,Rewa \\ ${ }^{3}$ Assistant Professor, Department of Obstetrics and Gynaecology, S.S. Medical College ,Rewa \\ Corresponding Author \\ Dr. Kalpana Yadav \\ Assistant Warden Quarter, Shristi Hotel, Hospital campus, S.S. Medical College Rewa (M.P.) \\ Email: yadavkalpana282@gmail.com
}

\begin{abstract}
Objectives: To study the association of thyroid hypofunction with increasing age in pregnant women with hypertension

Design: Prospective, observational, cohort study.

Setting: Study was carried out in Department of Obstetrics and Gynaecology, S.S.M.C and associated G.M. Hospital Rewa, Madhya Pradesh during the period of $1^{\text {st }}$ August 2015 to $31^{\text {st }}$ July 2016.

Study Population: In the study 200 women were recruited in which 100 women were taken as cases and 100 were taken as control. Study population was selected randomly from women visiting to the outdoor and those admitted in antenatal ward.

Participants: Cases: Women visiting the outdoor or those admitted in antenatal ward with diagnosis of gestational hypertension or preeclampsia where the case was defined on the basis of inclusion and exclusion criteria

Controls: Women visiting the outdoor or those admitted in antenatal ward without gestational hypertension or preeclampsia.

Main Outcome Measure(s): Results: Incidence of hypothyroidism increased with age from 12.5\%(1 out of 18), to $12.8 \%$ (6 out of 47), then to 41.9\%(13 out of 31) and then further to 50\%(7 out of 14) in age group $<20$ years, 20-24 years, 25-29 years and $\geq 30$ years respectively.

Conclusions: A positive association is present between increasing ageand incidence of hypothyroidism (clinical and subclinical) in antenatal patients having hypertension. This shows that the incidence of hypothyroidismincreases with agein women with hypertension in pregnancy and age is significantly
\end{abstract}


associated with hypothyroidism in the study group. Keywords: Hypertension,Thyroid Hypofunction, Gestational Hypertension , Preeclampsia

\section{Introduction}

Thyroid dysfunction constitutes one of the commonest endocrine disorders during pregnancy after diabetes mellitus [1]

Preeclampsia (PE) and gestational hypertension (GHTN) are new onset hypertensive disorders in pregnancy, occurring after mid-gestation after 20 weeks of gestation up to 6 weeks postpartum inpreviously normotensive non-proteinuric pregnant women with proteinuria (more than 300 $\mathrm{mg} / \mathrm{l}$ in 24 hours specimen) and without proteinuria respectively[2]. They affect up to 5$15 \%$ of pregnancies and are important risk factors for maternal and fetal morbidity and mortality [3] Pregnancy is associated with profound modifications in the regulation of thyroid function. These changes are the result of the various factors like an increase of thyroid-binding globulin (TBG) due to elevated estrogens and human chorionic gonadotropin (HCG), increased renal losses of iodine due to increased glomerular filtration rate, modifications in the peripheral metabolism ofmaternal thyroid hormones and modifications in iodine transfer of placenta.Hypothyroidism is also awell-known side-effect of anti-VEGF treatment due to capillary regression in the thyroid tissue. Although, pregnancy is usually associated with very mild hyperthyroxinemia which is the presence of free thyroxin (FT4) value above the 2.5th percentile with a thyrotropin (TSH) level within the reference range [4] ,but womencomplicated with preeclampsia have high incidence of hypothyroidism that might correlate with the severity of preeclampsia.Long term thyroid dysfunction may result from the effects of exposure to anti-angiogenic factors during pregnancy complicated by preeclampsia or gestational hypertension. Thyroid dysfunction in early pregnancy has also been associated with the development of preeclampsia and gestational hypertension in some studies, but not in all.
Women with subclinical hypothyroidism identified during pregnancy have an increased risk for severe preeclampsia when compared with euthyroidwomen. Hence, thyroid function tests should be performed in all pregnantwomen with hypertension during pregnancy.

\section{Objective}

To study the association of ThyroidHypofunction with increasing age in pregnant women with hypertension.

\section{Methodology}

Study Design: Prospective observational Cohort study.

Study Centre: Shyam Shah Medical College \& Gandhi Memorial Hospital, Rewa.

Study Population: In the study 200 women were recruited in which 100 women were taken as cases and 100 were taken as control.Study population was selected randomly from women visiting to the outdoor and those admitted in antenatal ward.

\section{Inclusion \& Exclusion Criteria}

Inclusion Criteria:

1. Pregnant women with age 17-35 years.

2. Pregnant women with gestational age above 20 weeks.

3. Women with pregnancy induced hypertension.

4. Women with no other systemic illness.

5. Women with single intrauterine gestation Exclusion Criteria:

1. All pregnant women with history of thyroid disease (hypo or hyperthyroidism, goitre, grave's disease, autoimmune and toxic nodular thyroiditis etc.)

2. Systemic disorders (diabetes, renal disease, epilepsy or other convulsive disorders, chronic hypertension, autoimmune and collagen vascular diseases) 
3. Multiple pregnancy.

4. H/o intake of any medication that might affect thyroid function, drugs like glucocorticoids, phenobarbitone, levothyroxine, methimazole, propylthiouracil and other anti-thyroid medications.

5. Pregnant women with gestational age $<20$ weeks.

6. Cases and controls lost on follow-up

Study Period: From 1st August 2015 to 31st July 2016.

Case: Women visiting the outdoor or those admitted in antenatal ward with the diagnosis of gestational hypertension or preeclampsia, where the case was defined on the basis of inclusion and exclusion criteria. Preeclampsia is a pregnancy specific syndrome characterized by elevation of blood pressure of more than $140 \mathrm{~mm}$ of $\mathrm{Hg}$ systolic or more than $90 \mathrm{~mm}$ of $\mathrm{Hg}$ diastolic with proteinuria (more than $300 \mathrm{mg} / \mathrm{l}$ in 24 hours specimen) after 20 weeks of gestation in previously normotensive non-proteinuric pregnant women. Gestational hypertension is characterized by new onset elevation of blood pressure of more than or equal to $140 \mathrm{~mm}$ of $\mathrm{Hg}$ systolic or more than or equal to $90 \mathrm{~mm}$ of $\mathrm{Hg}$ diastolic after 20 weeks of gestation in absence of proteinuria.

Control: The control constituted of equal number of matched age, parity, socio-demographic status, gestational age; healthy normotensive pregnant women visiting the outdoor or those admitted in antenatal ward.

\section{Method of Study}

Written informed consent from all participants recruited in study was taken after they had been made aware of purpose of study. Particulars of the women were noted such as name, age, symptoms, menstrual history for menarche, last menstrual period and past menstrual cycles, history ofpresent pregnancy. Both cases and controls were classified into upper, middle, and lower socio economic status. Past obstetric history was asked for duration of marriage, infertility, gravidity and parity status, recurrent abortions, preeclampsia, growth restriction, low birth weight, preterm delivery, prematurity, late pregnancy losses, neonatal deaths, and mental retardation in previous pregnancy. Past medical history was asked for any associated medical disorders like diabetes, thyroid disorders, exposure to radiation or autoimmune disorders. Significant surgical history and family history was also asked. A thorough clinical examination including height, weight, pulse, blood pressure, pedal edema, thyroid enlargement etc. was done followed by systemic examination. In obstetric examination fundal height, presentation and amount of liquor was noted and fetal heart sound was auscultated with stethoscope.

\section{Investigations}

All preliminary and baseline investigations like complete blood count, blood grouping and typing, urine routine and microscopy, HBsAg, HIV and blood sugar were done along with USG. Ultrasonography was done for fetal growth, liquor and placenta. All investigations pertaining to the complications of preeclampsia were also done like liver and kidney function tests, serum uric acid, platelet count and after that thyroid function test was performed.

\section{Procedure}

Assessment of thyroid status of cases and control was done with serum Free T3, T4 and TSH, for which $10 \mathrm{ml}$ venous blood sample was taken from the cubital vein irrespective of status of last meal, test was done before the initiation of any treatment and before the delivery. All samples were sent to the laboratory where sera was separated and stored at -200C until assayed. Free T3 (tri-iodothyronine), free T4 (thyroxine) and TSH (thyroid-stimulating hormone) were measured using fully automated chemiluminescence system (CLIA kits). Further, dependingupon the FT4 and FT3 values all women were classified as follows. 
Classification according FT3, FT4 and TSH levels:

\begin{tabular}{|c|c|c|c|}
\hline Functions & TSH & Free T3 & Free T4 \\
\hline $\begin{array}{c}\text { Clinical } \\
\text { hypothyroidism }\end{array}$ & Elevated & Low & Low \\
\hline $\begin{array}{c}\text { Subclinical } \\
\text { hypothyroidism }\end{array}$ & Elevated & Normal & Normal \\
\hline $\begin{array}{c}\text { Euthyroid } \\
\text { Subclinical } \\
\text { hyperthyroidism }\end{array}$ & Normal & Normal & Normal \\
\hline $\begin{array}{c}\text { Clinical } \\
\text { hyperthyroidism }\end{array}$ & Low & Normal & Normal \\
\hline
\end{tabular}

Guidelines for trimester specific serum TSH levels

(Recommended by American Thyroid Association Taskforce on Thyroid Disease during Pregnancy and Postpartum) [5]

Recommended Trimester Specific TSH levels:

\begin{tabular}{|c|c|c|c|}
\hline Trimester & FT3 & FT4 & TSH \\
\hline First & $1.91-3.5$ & $0.86-1.77$ & 0.1 to 2.5 \\
Trimester & $\mathrm{pg} / \mathrm{ml}$ & $\mathrm{pg} / \mathrm{ml}$ & $\mathrm{pg} / \mathrm{ml}$ \\
\hline Second & $2.8-4.2$ & $0.63-1.29$ & 0.2 to 3.0 \\
Trimester & $\mathrm{pg} / \mathrm{ml}$ & $\mathrm{pg} / \mathrm{ml}$ & $\mathrm{pg} / \mathrm{ml}$ \\
\hline Third & $2.4-4.1$ & $0.66-1.12$ & 0.3 to 3.0 \\
Trimester & $\mathrm{pg} / \mathrm{ml}$ & $\mathrm{pg} / \mathrm{ml}$ & $\mathrm{pg} / \mathrm{ml}$ \\
\hline
\end{tabular}

Statistical analysis: The data of the study were entered and analysed using the software Microsoft Excel 2013 for windows. Appropriate univariate and bivariate analysis were carried out using the Student $\mathrm{t}$ test for the continuous variable / proportion test ( $\mathrm{z}$ test / $\mathrm{t}$ test) and two-tailed Fisher exact test or chi-square $\left(\chi^{2}\right)$ test for categorical variables. The critical levels of significance of the results were considered at $5 \%$ i.e. $P<0.05$ was considered significant.

\section{Results}

Majority ofwomen with pregnancy induced hypertension were having mild preeclampsia (63\%) followed by severe preeclampsia (23\%) andgestational HTN (14\%)(Table No.1) Majority of women in study group (73\%) as well as in control group (89\%) were Euthyroid (EU). In the study group, cases of sub clinical Hypothyroidism (SCH) as well as clinical Hypothyroidism $(\mathrm{CH})$ were more in comparison to control group. No cases were hyperthyroid (HYPER) in study as well as in control group. (Table No. 2) In the study group and control group maximum number of women were between 20-29 yearsof age as this is the predominant age of reproduction.

Incidence of thyroid hypofunction increases with increasing age in bothgroups. In the study group incidence of hypothyroidism increased with agefrom $12.5 \%$ (1 out of 18 ), to $12.8 \%$ (6 out of 47 ), then to $41.9 \%$ (13 out of 31 ) and then further to $50 \%$ (7out of 14 ) in age group <20 years, 20-24 years, 25-29 years and $\geq 30$ yearsrespectively i.e. a positive association is present between increasing age and incidence of hypothyroidism.

Table 1: Distribution of cases according to severity of hypertension

\begin{tabular}{|c|c|}
\hline PIH & $\begin{array}{c}\text { Study group } \\
\mathrm{n}=100(\%)\end{array}$ \\
\hline $\begin{array}{c}\text { Gestational hypertension } \\
(\text { GHTN })\end{array}$ & 14 \\
\hline Mild preeclampsia & 63 \\
\hline Severe preeclampsia & 23 \\
\hline Total & 100 \\
\hline
\end{tabular}

Table 2: Distribution of cases according to thyroid status

\begin{tabular}{|c|c|c|}
\hline $\begin{array}{c}\text { Thyriod } \\
\text { Status }\end{array}$ & $\begin{array}{c}\text { Study Group } \\
(\mathrm{N}=100)\end{array}$ & $\begin{array}{c}\text { Control Group } \\
(\mathrm{N}=100)\end{array}$ \\
\hline EU & 73 & 89 \\
\hline SCH & 23 & 10 \\
\hline CH & 4 & 1 \\
\hline HYPER & 0 & 0 \\
\hline TOTAL & 100 & 100 \\
\hline
\end{tabular}


Table 3: Distribution of cases with thyroid disorders according to age (in year)

\begin{tabular}{|c|c|c|c|c|c|c|c|c|}
\hline \multirow{2}{*}{ Age Group } & \multicolumn{4}{|c|}{ Study Group $(\mathrm{n}=100)$} & \multicolumn{4}{c|}{ Control Group $(\mathrm{n}=100)$} \\
\cline { 2 - 10 } & EU & SCH & CH & TOTAL & EU & SCH & CH & TOTAL \\
\hline$<20$ & 7 & 1 & 0 & 8 & 5 & 0 & 0 & 5 \\
\hline $20-24$ & 41 & 6 & 0 & 47 & 67 & 3 & 0 & 70 \\
\hline $25-29$ & 18 & 11 & 2 & 31 & 16 & 7 & 1 & 24 \\
\hline$\geq 30$ & 7 & 5 & 2 & 14 & 1 & 0 & 0 & 1 \\
\hline TOTAL & 73 & 23 & 4 & 100 & 89 & 10 & 1 & 100 \\
\hline
\end{tabular}

\section{Discussion}

In our study, maximum number of women were between 20-29 years of age in study group (80\%) and control group (94\%) as this is the predominant age of reproduction.

Incidence of thyroid hypofunction increases with increasing age in both groups.Among the casesin the present study, incidence of hypothyroidism increased with age from $12.5 \%$ (1 out of 18 ), to $12.8 \%$ (6 out of 47 ), then to $41.9 \%$ (13 out of 31 ) and then further to $50 \%$ (7 out of 14) in age group $<20$ years, 20-24 years, 25-29 years and $\geq 30$ years respectively.

Comparable to our study, G. Shobhaet al(2005)[6], showed that incidence of thyroid hypofunction increases with increasing maternal age.

Allan et al (2000)[7] and VaidyaBet al(2007)[8] also found thatincreasing maternal age is a risk factor for hypothyroidism.

\section{Conclusions}

A positive association is present between increasing age and incidence of hypothyroidism (clinical and subclinical) in antenatal patients having hypertension. This shows that the incidence of hypothyroidism increases with age in women with hypertension in pregnancy and age is significantly associated with hypothyroidism in the study group.

\section{References}

1. Negro R, Farmoso G, Mangieri T, et al. Levothyroxine treatment in euthyroid pregnant women with autoimmune thyroid disease: effects on obstetrical complications. J ClinEndocrinolMetab. 2006;91:2587-91.

2. Dukkitt K, Harrington D. Risk factors for preeclampsia antenatal booking: Systemic review of controlled studies. BMJ. 2005; 330:565-567

3. Dutta DC. Hypertensive disorders in pregnancy. In Text book of Obstetrics including perinatology and contraception.6th edition. Calcutta: New central book agency ; 2004: 221-242.

4. Borst GC, Eil C, Burman KD. Euthyroidhyperthyroxinemia. Ann Intern Med. Mar 1983;98(3):366-78.

5. Stagnaro green A. Guidelines of the American Thyroid Association for the Diagnosis and Management of Thyroid Disease During Pregnancy and Postpartum. 2011 ;21(10) :1081-1125.

6. Shobha G, Rajeswari B, Srividya R. Prevalence of hypothyroidism in antenatal women attending OPD at Gandhi hospital. Panic Journ Med Scien.2015 Dec;5(3):150-152.

7. Haddow JE, Palomaki GE, Allan WC, Williams JR, Knight GJ, Gagnon J, et al. Maternal thyroid deficiency during pregnancy and subsequent neuropsychologicaldevelopment of the child. N Engl J Med 1999;341:549-55.

8. Vaidya B, Antony S, Bilosum. Detection of thyroid disfunction in early pregnancy: Universal screening of high risk targeted case finding. J ClinEndocrinol Metab.2007;92(1):203-7 